\title{
Ophthalmic molluscum contagiosum: clinical and immunopathological features
}

\author{
D G Charteris, R E Bonshek, A B Tullo
}

\begin{abstract}
Aims-A study of ophthalmic molluscum contagiosum infection was undertaken to define its clinical presentation and immunopathological features.

Methods-Retrospective analysis of 35 cases of histologically proved molluscum contagiosum infection was carried out. Diagnosis was delayed in $40 \%$ of cases resulting in repeated clinic visits.

Results-Twenty one patients were noted to have ocular surface changes; two patients were immunocompromised. All cases were eventually treated by excision of the lesion (19 had cautery to the lesion base) and there was recurrence in two cases. Immunohistochemical analysis of biopsy specimens showed that $T$ lymphocytes were a consistent finding in adjacent dermis and epidermis although they did not infiltrate the molluscum lesions. Smaller numbers of macrophages were also demonstrated. There was a notable cross reactivity by a $T$ cell antibody to the molluscum bodies.

Conclusion-The study shows the varied presentation of molluscum contagiosum infection to the ophthalmologist and the nature of the local immune response to the virus.
\end{abstract}

(Br f Ophthalmol 1995; 79: 476-481)

Molluscum contagiosum is an infection caused by a DNA poxvirus. ${ }^{1}$ Lesions are typically pale, round, raised, painless skin nodules with umbilicated centres. They may be widespread though the virus commonly infects the face including the eyelid margin. ${ }^{12}$ Lesions may be inconspicuous and in some cases are presumed to excrete virus onto the ocular surface. ${ }^{3}$ Chronic follicular conjunctivitis and corneal changes consisting of superior micropannus and fine epithelial keratitis may subsequently develop. ${ }^{2}$

The spectrum of ocular manifestations of molluscum contagiosum infection is not well

Table 1 Diagnosis

Diagnosis at initial clinical visit: 21 cases $(60 \%)$ (14 of these cases referred with eyelid lesions)

Diagnosis at subsequent clinic visits: 14 cases $(40 \%)$

these required 1-7 further visits (mean 3.1) for the diagnosis to be made

this represents a delay in diagnosis of 1-26 weeks (mean $11 \cdot 1$ weeks)

Alternative diagnoses offered:

lid lesions: basal cell carcinoma, papilloma, chalazion, sebaceous cyst, keratoacanthoma, wart, blepharitis, eczema, blocked nasolacrimal duct, ectropion conjunctiva: allergic, bacterial, viral, and chlamydial conjunctivitis

conjunctivitis

Duration of symptoms (at presentation): 1 week to 18 months documented. A retrospective study of histologically proved ophthalmic molluscum contagiosum infection was therefore undertaken to define its clinical presentation and to investigate the potential for misdiagnosis. Likewise the immune response to infection with molluscum contagiosum is not yet defined and an immunohistochemical study was accordingly undertaken to characterise the cellular response to this infection.

\section{Materials and methods}

\section{PATIENTS}

Using the database of the pathology department all biopsy specimens from Manchester Royal Eye Hospital which were positive for molluscum contagiosum during the period 1981-93 were identified. A retrospective analysis of this group was carried out using hospital case notes (additional cases may have been treated without pathological analysis of specimens). The following variables were recorded: age, systemic illnesses, symptoms at presentation, and duration; ophthalmic findings including visual acuity, eyelid, conjunctival, corneal, and other manifestations at presentation; number of previous clinic visits and alternative diagnoses; treatment, recurrences, and pathological findings.

\section{IMMUNOHISTOCHEMISTRY}

Biopsy specimens were reviewed to identify those where sufficient tissue remained for immunohistochemical analysis. This was

\section{Table 2 Clinical findings}

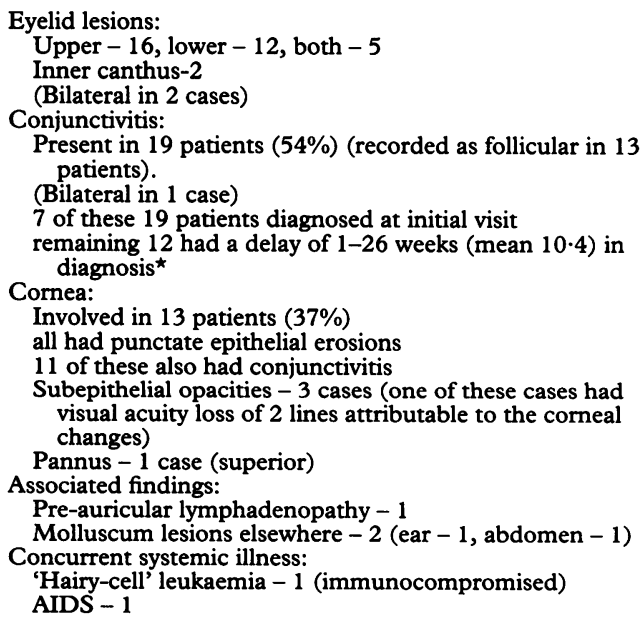

*Comparison in the delay in diagnosis of conjunctivitis (overall mean 6.6 weeks) $v$ non-conjunctivitis patients (overall mean 


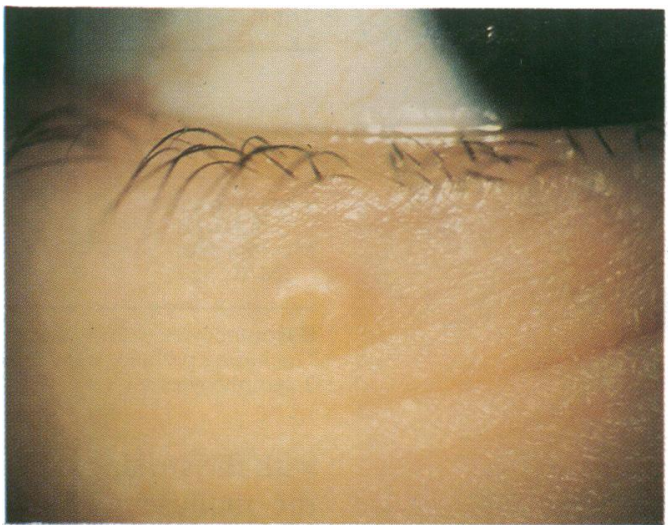

Figure 1 Typical pale, umbilicated skin nodule caused by molluscum contagiosum infection.

carried out using primary monoclonal antibodies to T lymphocytes (CD45RO, UCHL1, Dako, High Wycombe), B lymphocytes (CD 20, L26, Dako) and monocytes/macrophages (L1 antigen, MAC 387, Dako), and a rabbit polyclonal antibody to $\mathrm{T}$ lymphocytes $(\mathrm{CD} 3$, Dako).

Tissue sections of $5 \mu \mathrm{m}$ were dewaxed and rehydrated, and endogenous peroxidase activity was quenched by incubating sections in 3\% (v/v) hydrogen peroxide (30 vol) in distilled water for 5 minutes. The sections were then washed in distilled water and placed in TRIS buffered saline (TBS): $0.05 \mathrm{M}$ TRIS/HCl, $0 \cdot 15 \mathrm{M} \mathrm{NaCl}, \mathrm{pH} 7 \cdot 6$, for 5 minutes, following which they were incubated for 20 minutes in normal goat serum diluted 1:5 in TBS. After removal of serum, primary antibody was applied at an optimised dilution for 20 minutes. The sections were then washed and the primary antibody localised using Dako StreptABCComplex/HRP Duet kit (Dako) and 3,3'-diaminobenzidine tetrahydrochloride (DAB) (Sigma UK, Poole, Dorset) as chromogen according to the protocol described in the kit. In each run, sections of tonsillar tissue were used as positive controls for each antibody and primary antibody was replaced with TBS for a negative control. To ensure specificity of CD3 antibody staining, a run was carried out in which each case was incubated with anti-CD3 polyclonal antibody preabsorbed with synthetic human $\mathrm{CD} 3$ peptide (Dako) at $0.5 \mu \mathrm{g} / \mathrm{ml}$ for 30 minutes.

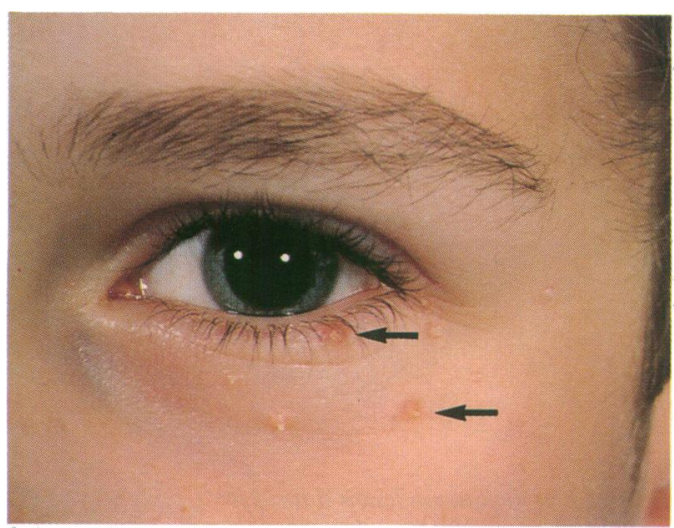

Figure 2 Multiple periocular molluscum lesions, two of which show mild secondary inflammation (arrows).

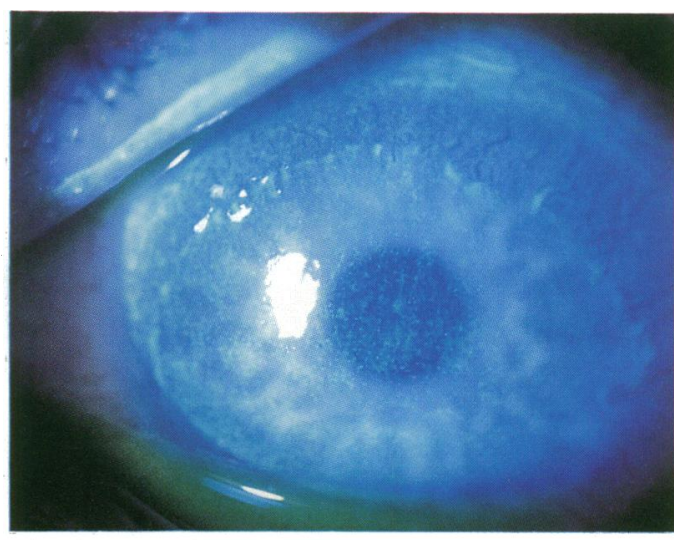

Figure 3 Punctate epithelial keratitis secondary to molluscum infection.

The intensity of the cellular infiltrate for each antibody was graded on a scale of 0 to ++++ .

\section{Results}

A total of 35 patients (20 female and 15 male) were identified with a positive pathological diagnosis of molluscum contagiosum. The age range was 3-61 years (mean 25.5 years). Tables 1 and 2 give details of diagnosis and clinical findings. Of the 35 cases 16 were treated by excision alone and 19 were treated by excision and cautery. Two patients had a recurrence of the lesion, both initially treated by excision and cautery. Figures 1-4 illustrate some of the typical clinical findings in these cases.

Two patients in the series were known to be immunocompromised. A 36-year-old man with AIDS presented with two upper eyelid nodules one of which was very large and atypical for a molluscum lesion (Fig 5) and a small ipsilateral lower eyelid nodule. The large nodule had been present as a small lesion for many years and had increased in size markedly before excision. He also had quiescent retinal changes from CMV retinitis but no other ocular disease related to molluscum infection. At the time the lesion was biopsied this patient's absolute CD4 T cell count was 6 and his CD4 $\mathrm{T}$ cell count was less than $2 \%$ of the total $T$ cell count. A 60 -year-old man, immunocompromised from 'hairy cell' leukaemia, presented with one small upper

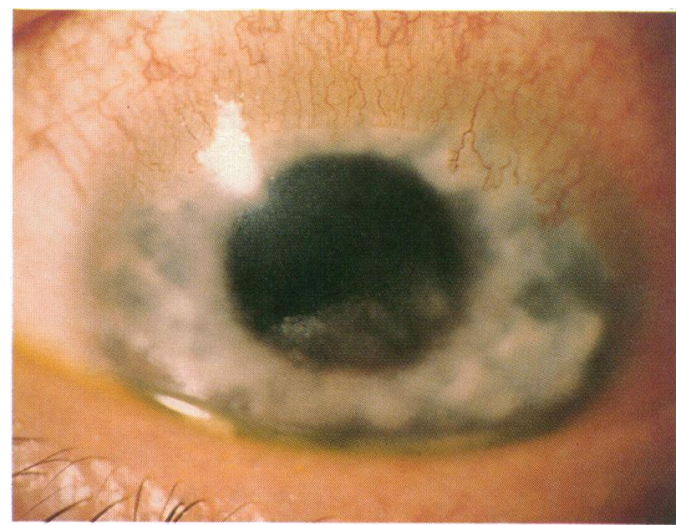

Figure 4 Superior corneal micropannus caused by chronic molluscum keratoconjunctivitis. 


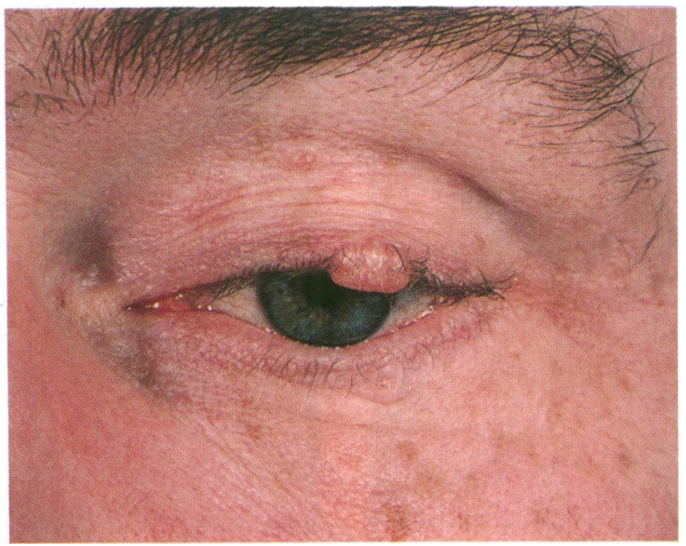

Figure 5 'Giant' upper lid molluscum nodule in a patient suffering from $A I D S$.

eyelid nodule and a mild punctate epithelial keratitis. Neither of these patients had recurrence of molluscum lesions.

Twenty one specimens provided sufficient tissue for immunohistochemical analysis of the molluscum lesion and adjacent skin. The immunopathological findings in these 21 cases are documented in Table 3 . In all cases there was an infiltrate of $T$ lymphocytes. The $T$ cell infiltrate was consistently moderate to heavy $(++/+++)$ in the morphologically normal epidermis surrounding the lesions. $T$ cells were also consistently found in the adjacent dermis although generally the infiltrate was less heavy in this location $(+/++)$ (Figs 6 and 7). No T lymphocytes were found within the central area of typically infected cells containing molluscum bodies. No L26 positive B lymphocytes were found in any of the specimens, although in a few biopsies occasional plasma cells were identified morphologically within the adjacent dermis.

The pattern of staining with the CD3 antibody was similar to that seen with UCHL1
Table 3 Immunopathological findings

\begin{tabular}{llllll}
\hline & \multicolumn{4}{l}{$\begin{array}{l}\text { Intensity of infiltrate to dermis/epidermis } \\
\text { surrounding molluscum lesion }(n=21)^{*}\end{array}$} \\
\cline { 2 - 6 } & Negative & + & ++ & +++ & ++++ \\
\hline $\begin{array}{c}\text { T lymphocytes } \\
\text { (UCHL1) }\end{array}$ & 0 & 0 & 4 & 16 & 1 \\
$\begin{array}{c}\text { Macrophages } \\
\text { (MAC 387) }\end{array}$ & 7 & 13 & 0 & 1 & 0 \\
\hline
\end{tabular}

B lymphocytes (L26) - negative in all specimens.

*Including pathologically inflamed lesions $(n=2)$ graded as:

T lymphocytes $=+++1+++$; macrophages $=+1+++$.

with the striking exception that material within the molluscum bodies stained heavily in all cases (Fig 8). The specificity of this staining was confirmed by preabsorption with the $\mathrm{CD} 3$ antiserum immunogen, synthetic human CD3 peptide. All T cell and molluscum body staining was abolished. In addition no background stain was seen.

In two specimens the lesions had a heavy mixed inflammatory cell infiltrate within and surrounding the collection of infected cells. In these lesions there was a significant population of MAC 387 positive histiocyte/macrophages $(+/+++)$. Clinically, neither of these lesions was noted to be inflamed. Small numbers of MAC 387 positive cells were also identified in 12 other specimens (Fig 9) within the dermis adjacent to the molluscum lesions, none of which were clinically inflamed. Although the MAC 387 antibody also recognises granulocytes, morphologically none of these cells were identified in the tissue sections.

The biopsy from the patient with AIDS notably contained a mixed $\mathrm{T}$ lymphocyte (UCHL1 positive) and histiocyte (MAC 387 positive) infiltrate in the dermis and epidermis surrounding the lesion. In the immunocompromised patient suffering from leukaemia there was only a scanty infiltrate of

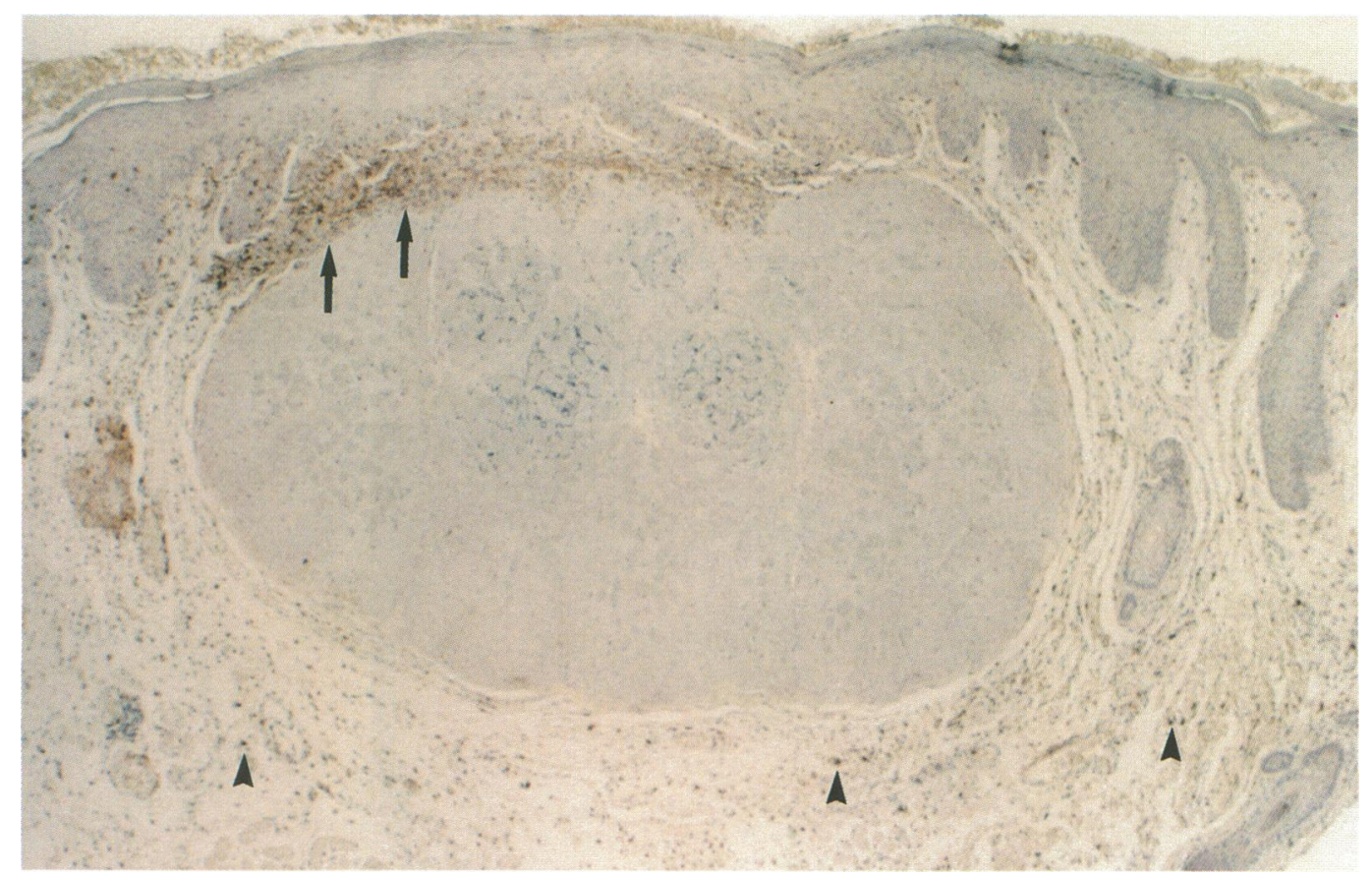

Figure 6 Low powered photomicrograph of molluscum lesion stained for T lymphocytes (UCHL1). There is an intense infiltrate of $T$ cells between the molluscum nodule and the adjacent epidermis (arrows). Scattered T cells are also present in the surrounding dermis and epidermis (arrowheads to examples). Note that there are no UCHL1 positive $T$ cells within the molluscum lesion itself. 3,3'-diamino-benzidine tetrahydrochloride (DAB), haematoxylin counterstain. $\times 50$. 


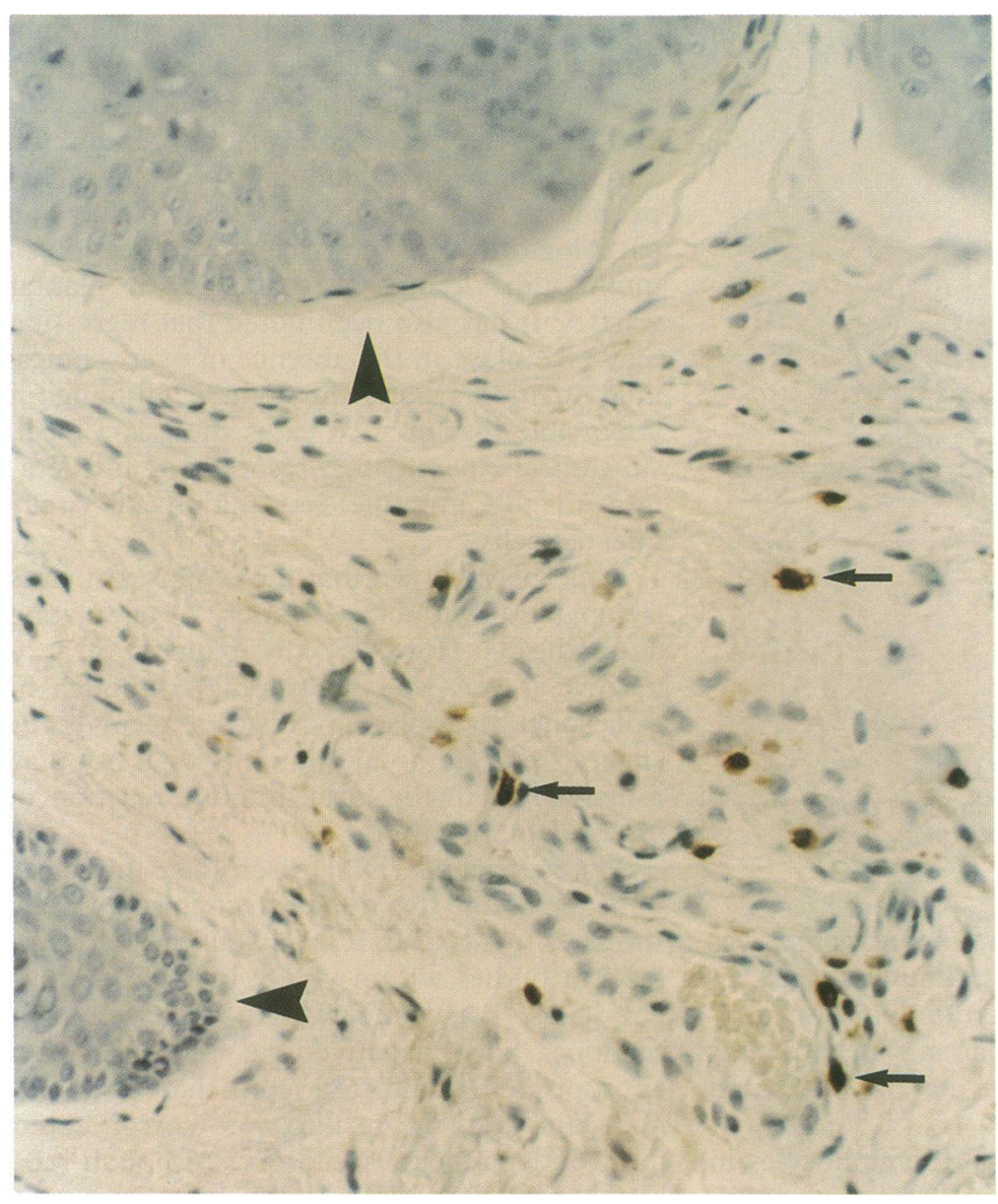

Figure 7 UCHL1 positive T cells (arrows to examples) in the dermis below a molluscum lesion (arrowheads). DAB, haematoxylin counterstain. $\times 262$.

lymphocytes in the tissues surrounding the molluscum lesion.

\section{Discussion}

This clinical study of 35 patients with histologically proved molluscum contagiosum demonstrates that infection can present to the ophthalmologist in a variety of ways manifesting as eyelid, conjunctival, and corneal disease, predominantly in young adults. Only $60 \%$ of cases were diagnosed at the initial clinical visit and it is clear that there can be considerable delay in appropriate treatment resulting in multiple clinic visits. This was especially true of patients presenting with conjunctivitis rather than lid nodules (Table 2) suggesting that the ocular surface manifestations may often be the result of inconspicuous molluscum lesions, particularly among the lashes. Previous reports have emphasised that, while recognition of the classic molluscum nodule should present no diagnostic difficulties, lesions in the region of the eyelids can assume an atypical appearance which may be misleading. ${ }^{3}$ The clinical findings in this study therefore underline the need for an index of clinical suspicion for the possibility of molluscum contagiosum infection in undiagnosed lid lesions, chronic follicular conjunctivitis, and/or superficial punctate keratitis. Since all the cases had histologically proved lesions it is possible that cases where treatment was undertaken without excision, when the clinician may be more certain of the diagnosis, could have a somewhat different clinical spectrum. Our findings none the less are evidence that there is considerable potential for misdiagnosis in periocular molluscum contagiosum infection.

There has been a recently reported increase in the number of cases of molluscum contagiosum infection occurring in immunocompromised patients and, in particular, in AIDS patients. $^{56}$ In our series two patients were immunocompromised (one from AIDS and one from leukaemia) and although both cases were already diagnosed they illustrate that molluscum contagiosum infection can serve as a marker for other, more serious infections which may in some cases be sexually transmitted. ${ }^{7}$ The 'giant' molluscum lesion excised from the AIDS patient is in keeping with the gross manifestations of molluscum infection which have been described in other AIDS patients. ${ }^{56}$ It is notable that despite the immunocompromised status of these patients,

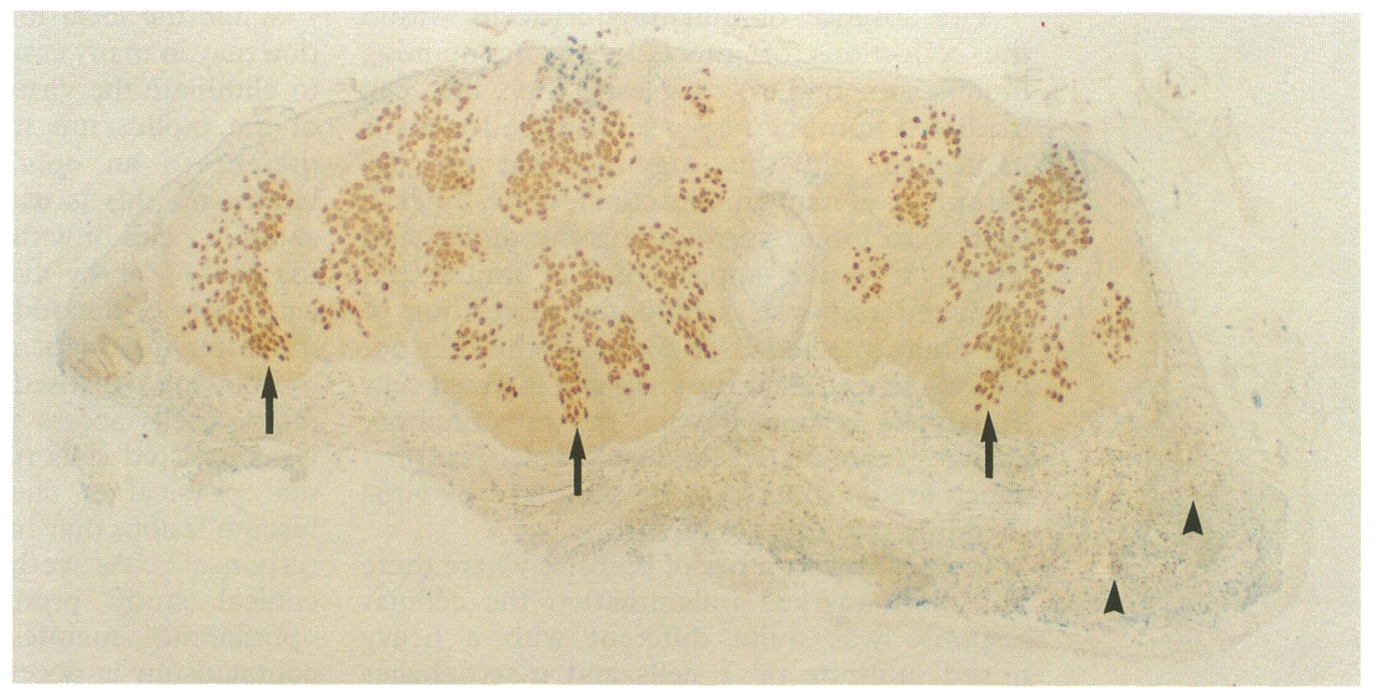

Figure 8 CD3 stain of molluscum lesion demonstrating intense labelling of molluscum bodies (arrows to examples). $T$ lymphocytes in the surrounding dermis also stain positively (arrowheads to examples). $D A B . \times 25$. 


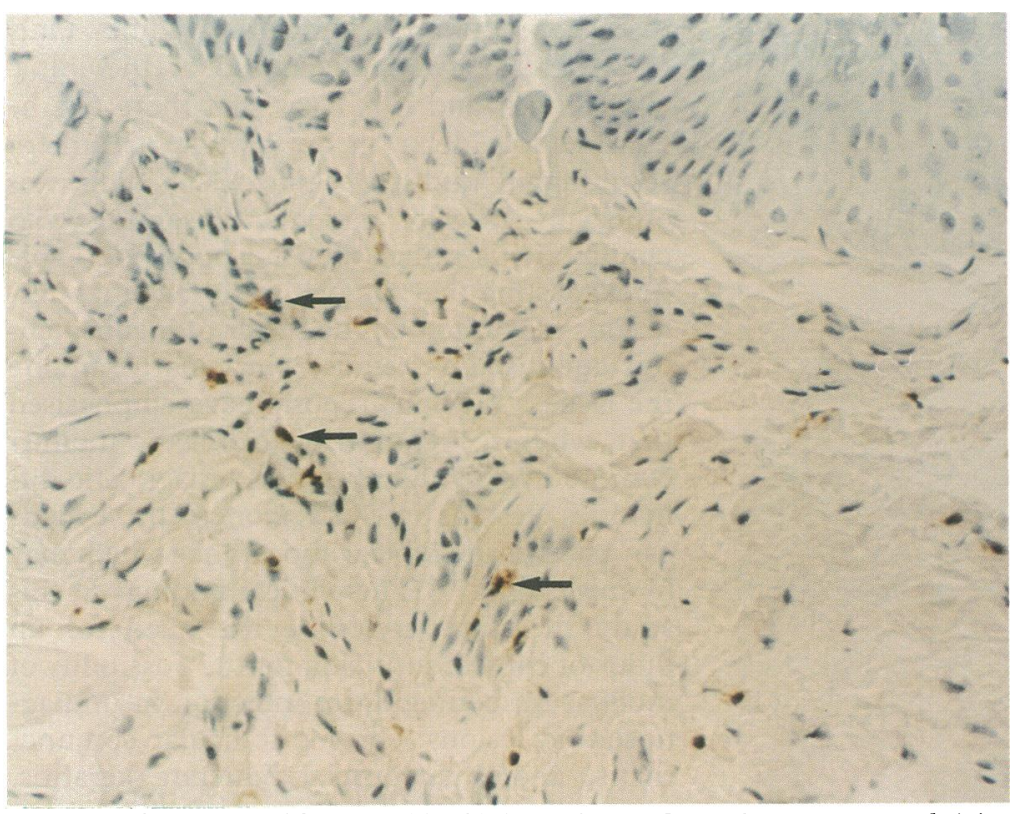

Figure 9 Scattered MAC 387 positive histiocytes/macrophages (arrows to examples) in the dermis adjacent to molluscum lesion. $D A B$, haematoxylin counterstain. $\times 112$.

a local cell mediated immune response was found in the their biopsies. The increased incidence of (sometimes severe) molluscum contagiosum seen in AIDS patients nevertheless suggests that this response may be of limited efficacy.

The consistent finding of $\mathrm{T}$ lymphocytes in the epidermis and dermis surrounding the molluscum lesions suggests that they play a central role in the local immune response to infection with the virus. Smaller numbers of macrophages were also found in most biopsies implying that these cells are also actively involved in the tissue pathology. It is notable that very few of the lesions examined immunopathologically had been recorded as being clinically inflamed. The $T$ lymphocyte response is in contrast with the findings in other studies which reported an absence of a cellular immune response in noninflamed molluscum lesions. ${ }^{89}$ It is possible that the immune response to ocular molluscum contagiosum may differ from that elsewhere in the body although further studies will be necessary to clarify this.

The absence of inflammatory cells within the collections of infected cells (containing molluscum bodies) suggests that the cell mediated immune response in these lesions is ineffective and this may account for the chronicity of many molluscum lesions. Since T cells were found surrounding the molluscum lesions it would appear that a limited cell mediated response is mounted in relation to the virally infected cells. Although this may not be sufficient to clear the virus and infected cells it may be responsible for the inflammatory changes (conjunctivis and superficial keratitis) which are considered to be produced by virus shedding onto the conjunctiva.

In the small number of biopsies where there was more marked inflammation the cellular response was quite different with a heavy mixed infiltrate of $\mathrm{T}$ cells and macrophages around and within the molluscum lesion. This may represent a change in the immune recognition of the viral antigens with a subsequently more effective cellular immune response which clears the virus containing cells and leads to regression of the molluscum nodule. Such an inflammatory response has previously been recognised both clinically and pathologically as a precursor to regression of molluscum lesions ${ }^{10-12}$ and also plantar warts. ${ }^{13}$ It has also been noted that regression may take place in the absence of overt clinical inflammation around the nodule ${ }^{14}$ although it is possible that in such cases there is a local, subclinical inflammatory response or an alteration in the immune recognition of virally infected cells.

It has been shown that the molluscum virus is capable of inducing a variety of circulating antibodies. ${ }^{15}$ However, the paucity of L26 positive B cells and neutrophils (although in occasional cases plasma cells were recognised) suggests that humoral immunity does not play a major role in the local immune reaction to molluscum infection.

The pattern of $\mathrm{CD} 3$ antiserum staining was unusual. While this marker recognised $T$ cells similarly to UCHLl, the staining of molluscum bodies within virally infected epithelial cells was unexpected. The control sections, both negative and positive, were appropriate (uninfected epithelial cells did not stain) and the results were corroborated in an independent laboratory. Although rabbit antisera may intrinsically cross react with cytoskeletal elements, the preabsorption results confirm specific binding of the $\mathrm{CD} 3$ antibody. Furthermore, this pattern of staining has previously been described using an anti-macrophage monoclonal antibody ${ }^{8}$ on frozen sections, a feature considered to contribute to the lack of host recognition of molluscum contagiosum virus. Although an investigation of the nature of this apparent cross reactivity is outside the scope of this study, the potential for the existence of epitopes shared between virally infected cells and cells of the immune system could be of importance in the lack of immune recognition and response to the virus with resulting chronicity of the skin lesions.

While the local immune response to infection may in many cases, with time, be sufficient to eliminate the virus and produce regression of the molluscum nodule most cases which present to an ophthalmologist will require treatment; this is usually relatively simple by excision (with or without cautery to the base of the lesion) or by evisceration of the umbilicated core of the nodule. ${ }^{1}$ The effectiveness of the latter treatment may in part be produced by allowing sensitised $T$ cells and other inflammatory cells access to previously 'walled off' virus infected cells (it has been demonstrated that physical or chemical irritation of molluscum lesions may induce a systemic antibody response ${ }^{15}$ ). As we have demonstrated in the clinical study prompt recognition of the ophthalmic manifestations of molluscum contagiosum is necessary to prevent delay in the diagnosis and effective treatment of this infection. 
The authors would like to acknowledge the following: Graham Bigley, surgical histology department, Manchester Royal Bigley, surgical histology department, Manchester Royal
Infirmary, Oxford Road, Manchester M13 9WH and Dr S Infirmary, Oxford Road, Manchester M13 $9 \mathrm{WH}$ and Dr S Manchester for technical assistance.

Synthetic human $C D 3$ peptide was a gift from Dako Ltd, High Wycombe.

1 Epstein WL. Molluscum contagiosum. Semin Dermat 1992; 11: $184-9$.

Arffa RC. Graysons diseases of the cornea. 3rd edn. St Louis: Mosby, 1991: 306-8.

3 Curtin BJ, Theodore FH. Ocular molluscum contagiosum. Am $\mathcal{F}$ Ophthalmol 1955; 39: 302-7.

4 Mathur SP. Ocular complications in molluscum contagiosum. Br f Ophthalmol 1960; 44: 572-3.

$5 \mathrm{Kohn}$ SR. Molluscum contagiosum in patients with acquired immunodeficiency syndrome. Arch Ophthalmol 1987; 105: 458.

6 Robinson MR, Udell IJ, Garber PF, Perry HD, Streeten BW. Molluscum contagiosum of the eyelids in patients with acquired immune deficiency syndrome. Ophthalmology 1992; 99: 1745-7.
7 Oriel JD. The increase in molluscum contagiosum. $B M \mathcal{F}$ 1987; 294: 74 .

8 Heng MCY, Steuer ME, Levy A, McMahon S, Richman M, Allen SG, et al. Lack of cellular immune response in eruptive molluscum contagiosum. Am $\mathcal{F}$ Dermatopathol 1989; 11: 248-54.

9 Viac J, Chardonnet Y. Immunocompetent cells and epithelial cell modifications in molluscum contagiosum. f Cutan Pathol 1990; 17: 202-5.

10 Henao M, Freeman RG. Inflammatory molluscum contagiosum. Arch Dermatol 1964; 90: 479-82.

11 Kipping HF. Molluscum dermatitis. Arch Dermatol 1971 103: $106-7$.

12 Steffen C, Markman J-A Spontaneous disappearance of molluscum contagiosum. Arch Dermatol 1980; 116: 923-4.

13 Tagami H, Takigawa M, Ogino A, Imamura S, Ofugi S agami $\mathrm{H}$, Takigawa $\mathrm{M}$, Ogino A, Imamura $\mathrm{S}$, Ofugi $\mathrm{S}$.
Spontaneous regression of plane warts after inflammation. Arch Dermatol 1977; 113: 1209-13.

14 Lever WF, Schaumburg-Lever G. Diseases caused by viruses. In: Histopathology of skin. 6th edn. Philadelphia: Lippincott, 1983.

15 Shirodaria PV, Matthews RS. Observations on the antibody responses in molluscum contagiosum. $\mathrm{Br} \mathcal{f}$ Dermatol 1977; 96: 29-34. 